\title{
Improvement of the interface bonding between date palm fibers and polymeric matrices using alkali-silane treatments
}

\author{
Abdessamad Oushabi $^{1}$ - Fahd Oudrhiri Hassani ${ }^{2} \cdot$ Younes Abboud $^{1}$. Said Sair ${ }^{1} \cdot$ Omar Tanane $^{1} \cdot$ Abdeslam El Bouari $^{1}$
}

Received: 7 August 2018 / Accepted: 16 November 2018 / Published online: 30 November 2018

(c) The Author(s) 2018

\begin{abstract}
In this paper, the effect of chemical treatments on date palm fibers (DPFs) properties was studied; DPFs were first treated with a $5 \mathrm{wt} \% \mathrm{NaOH}$ aqueous solution for $1 \mathrm{~h}$ and then modified using two types of silane coupling agents (3-Mercaptopropyltrimethoxysilane and 3-Aminopropyltrimethoxysilane) with various concentrations $(0.1,0.5,1$ and $2 \mathrm{wt} \%)$ to improve the interfacial properties of DPFs with polymeric matrices. SEM observations showed the formation of silane layers on the alkalized surface of DPFs. The Fourier-transform infrared (FTIR) results showed that the salinization was successfully performed by forming covalent $\mathrm{Si}-\mathrm{O}-\mathrm{C}$ bonds between $\mathrm{DPF}$ and silane coupling agent. The pull-out behavior of treated fibers was also investigated using two matrices; polyurethane (PU) and epoxy. The obtained results showed that the treatments have successfully improved the interfacial bond characteristics of DPF-PU and DPF-Epoxy systems.
\end{abstract}

Keywords Date palm fibers $\cdot$ Alkali-silane treatment $\cdot$ Interfacial shear stress $\cdot$ Pull-out test $\cdot$ Epoxy $\cdot$ Polyurethane

\section{Introduction}

The last few years have seen a high demand for lignocellulosic fibers for the reinforcement of polymer composite materials [1-3]. Indeed, the applications of these fibers in composites are spreading in many sectors such as automotive, construction and sport [4]. This gain in interest stems from the combination of several advantages of lignocellulosic fibers compared to fibers conventionally used in composites, such as: low cost, low density, non-toxicity, high specific properties, no abrasion during processing, and the possibility of recycling [2].

Silane coupling agents (organosilanes) are compounds whose molecules contain functional groups that bond with both organic and inorganic materials; they are often used in many industrial applications to improve adhesion between a polymer matrix and inorganic materials. They are also used in the surface modification of plant fibers in polymer matrix

Abdessamad Oushabi

oushabiabdessamad@yahoo.fr

1 Laboratory of Physico-Chemistry of Applied Materials (LPCMA), University of Hassan II of Casablanca, Faculty of Sciences Ben M'sik, Driss El Harti, B.P 7955, Sidi Othmane, Casablanca, Morocco

2 National School of Applied Sciences (ENSA), Safi, Morocco composites [5, 6]. The general formula of an organosilane shows two classes of fractions attached to a silicon atom:

$R_{n} \mathrm{SiX}_{(4-n)}$.

$R$ is a non hydrolyzable organic moiety which may be an alkyl, aromatic, organofunctional group. These groups provide the organic compatibility which allows the silane to form inter-penetrating polymer networks or, in the case of reactive organofunctional silanes, to co-react with the polymer matrix.

$X$ represents alkoxy moieties, the most commonly encountered are methoxy $\left(-\mathrm{OCH}_{3}\right)$ or ethoxy $\left(-\mathrm{OC}_{2} \mathrm{H}_{5}\right)$, which react with the various forms of hydroxyl groups and release methanol or ethanol. These groups can readily provide bonds with inorganic substrates to improve adhesion [7].

As shown in Fig. 1, the reaction mechanism of the coupling of the organosilanes with the various substrates is linked to the effect of the two reactive groups, these reactions are different depending on the substrate in contact; On the one hand, the alkoxy groups allow the silane to bind to the surface hydroxyl groups and, on the other hand, the alkyl $(R$-) groups increase the compatibility and the hydrophobicity with the organic compounds, thus leading to an increase of The resistance of the interface between the two substrates [8]. 
Fig. 1 Adhesion mechanism between the organosilane and fiber surface
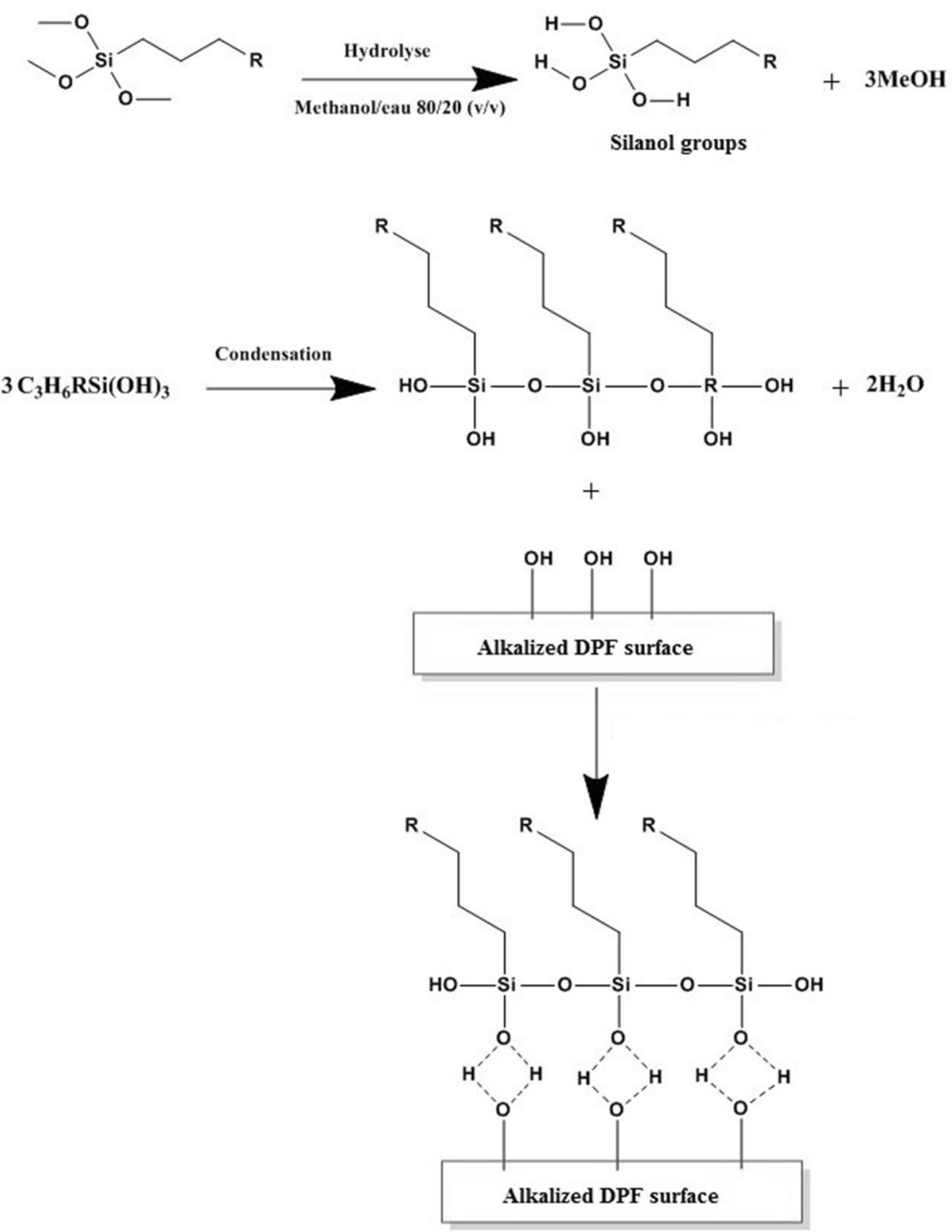

R= SH: 3-Mercaptopropyltrimethoxysilane (Silane A)

$\mathrm{R}=\mathrm{NH}_{2}$ : 3-Aminopropyltrimethoxysilane (Silane B)

The organosilane is often subjected to hydrolysis in a water/alcohol solution prior to treatment. After hydrolysis, a reactive silanol group is formed which can be condensed with other silanol groups to form siloxane bonds. Stable condensation products are also formed with other oxides such as those of aluminum, zirconium, titanium and nickel. Less stable bonds also form with oxides of iron and carbon. The alkali metal oxides and the carbonate do not form stable bonds with $\mathrm{Si}-\mathrm{O}$. It should be noted that a sufficient amount of water for the hydrolysis may be available from atmospheric moisture or on the surface of the substrate. In some cases, it may be necessary to add water to increase the degree of hydrolysis [7, 8].

The coupling of the organosilane ends with the formation of hydrogen bonds with hydroxy sites existing on the surface of the substrate. Finally, during drying or curing, a covalent bond is formed with the substrate and water is released [9] (Fig. 1).

Many studies have been carried out on several types of lignocellulosic fibers such as sisal [10], hemp [11], date palm [12], bamboo [13] and jute [14] and focused on the mechanical properties and chemical modifications to improve fiber/ polymer compatibility. Zhou et al. [15] have found that the 
silane treatment of sisal fibers modifies surface topography, surface chemical structure and thermal degradation of sisal fibers. Li et al. [10] studied the influence of the treatment of sisal fibers with 3-aminopropyltriethoxysilane in acetone with a concentration of $6 \%$ for $24 \mathrm{~h}$ on the performance of vinyl ester composites. The results obtained showed an improvement of $3 \%$ of the tensile strength and $14 \%$ of the tensile modulus of the composites. The strength and bending modulus of the silane fiber composites increased by $15 \%$ and $30 \%$, respectively, compared to the untreated composites. However, the treatment of the fibers by the silane did not affect the impact energy. Benzerzour et al. [5] studied the effects of silane treatment on the bond characteristics of recycled unsaturated polyester/glass fiber in a cementitious matrix, results showed an enhancement of the fiber-matrix interfacial properties in terms of the pull out energy and the bond strength with an optimal silane content of $0.5 \mathrm{wt} \%$. Michelena et al. [16] considered that addition of organosilane coupling agent to epoxy resin may be a good alternative to the direct chemical pre-treatment of lignocellulosic fibers before composites manufacture.

In this work, alkali treated date palm fibers were subjected to surface treatment by two types of silane coupling agents to improve the bond properties between the fibers and the matrix. Morphological, chemical and thermal changes of DPFs were investigated. The bond characteristics of the fibers in polyurethane and epoxy matrices were also studied using single fiber pullout test.

\section{Materials and methods}

\section{Materials}

The natural fibers used in this work are date palm fibers (Phoenix dactylifera L.) collected from the region of Errachidia in southeast of Morocco. DPFs were manually separated, washed in distilled water several times to remove waxes and soluble impurities and then dried in an oven at $80{ }^{\circ} \mathrm{C}$ for $24 \mathrm{~h}$.

The 3-mercatopropyltrimethoxysilane and 3-aminopropyltrimethoxysilane were supplied by Sigma Aldrich, France while Sodium hydroxide $(\mathrm{NaOH})$ was supplied by BDH Chemicals Ltd Poole England.
PU specimens were prepared using industrial raw materials; polyisocyanate was supplied by DOW chemicals (ISONATE 181 MDI Prepolymer), with weight percentage of NCO group and density of $23.0 \%$ and $1.20 \mathrm{~g} / \mathrm{cm}^{3}$, respectively, polyol (Krasol LBH 2000 Diol) was provided by CRAY VALLEY with hydroxyl value $0.91 \mathrm{meq} / \mathrm{g}$, the average functionality, hydroxyl functionality and density of the polyol are $19-20$ and $0.9 \mathrm{~g} / \mathrm{cm}^{3}$ at $20^{\circ} \mathrm{C}$, respectively. Epoxy resin used in this study (Araldite 506 epoxy resin) was supplied by Sigma Aldrich with a density of $1168 \mathrm{~g} /$ $\mathrm{cm}^{3}$.

\section{Methods}

\section{DPFs alkali treatment}

The alkali treatment of date palm fibers was carried out according to previous work [12], DPFs were treated with $5 \%$ of sodium hydroxide for $1 \mathrm{~h}$ at room temperature, and then they were rinsed several times with distilled water to remove the excess of unreacted $\mathrm{NaOH}$ solution, after that they were dried in an oven at $80{ }^{\circ} \mathrm{C}$ for $24 \mathrm{~h}$.

\section{Preparation of silane solutions and DPFs silane treatment}

The silane treatment of date palm fibers was performed using two silane agents; 3 -mercatopropyltrimethoxysilane and 3-aminopropyltrimethoxysilane namely silane $\mathrm{A}$ and silane B, respectively. Briefly, a 80/20 (v/v) mixture of methanol and water was prepared and stirred for $30 \mathrm{~min}$, $\mathrm{pH}$ of the solutions was adjusted with acetic acid, while stirring the aqueous solution, silane drops with various contents $(0.1,0.5,1$ and $2 \mathrm{wt} \%)$ were added gradually and slowly to ensure a good dispersion. The hydrolysis was then carried out at room temperature for $24 \mathrm{~h}$; after that alkali treated date palm fibers were added to each mixture and kept at room temperature for $24 \mathrm{~h}$. After the silane treatment, fibers were washed many times with a 80/20 (v/v) methanol/water mixture to remove residual unreacted silane molecules, washed in distilled water and dried in an oven at $80^{\circ} \mathrm{C}$. The abbreviation for the different fiber treatments used in this work is presented in Tables 1, 2.

Table 1 Nomenclature of different treatment used in this study

\begin{tabular}{|c|c|c|c|c|c|c|c|c|c|c|}
\hline \multirow[t]{3}{*}{ Treatment } & \multirow[t]{3}{*}{ Raw DPF } & \multirow[t]{3}{*}{ Alkali treated DPF } & \multicolumn{8}{|c|}{ Alkali-silane treated DPF } \\
\hline & & & \multicolumn{4}{|c|}{ 3-Mercatopropyltrimethoxysilane (silane A) (\%) } & \multicolumn{4}{|c|}{ 3-Aminopropyltrimethoxysilane (silane B) (\%) } \\
\hline & & & $0.1 \mathrm{wt} \%$ & $0.5 \mathrm{wt} \%$ & $1 \mathrm{wt} \%$ & $2 \mathrm{wt} \%$ & $0.1 \mathrm{wt} \%$ & $0.5 \mathrm{wt} \%$ & $1 \mathrm{wt} \%$ & $2 \mathrm{wt} \%$ \\
\hline Code & $\mathrm{RF}$ & Alk-DPF & A0.1 & A 0.5 & $\mathrm{~A} 1$ & $\mathrm{~A} 2$ & B0.1 & B0.5 & B1 & B2 \\
\hline
\end{tabular}


Table 2 Bond assignments of raw and treated DPFs

\begin{tabular}{|c|c|c|c|c|c|}
\hline \multicolumn{4}{|c|}{ Wavenumber $\left(\mathrm{cm}^{-1}\right)$} & \multirow[t]{2}{*}{ Functional groups } & \multirow[t]{2}{*}{ References } \\
\hline $\mathrm{RF}$ & Alk-DPF & Silane A & Silane B & & \\
\hline 3310 & 3350 & 3450 & 3448 & The $\mathrm{O}-\mathrm{H}$ stretching vibration from the cellulose of the sisal fiber & [12] \\
\hline 2920 & 2920.5 & $2920 ; 2896$ & 2920 & Symmetric and asymmetric stretching of $\mathrm{CH}_{2}$ groups & [12] \\
\hline 1746 & - & - & - & Stretching vibrations of the $\mathrm{C}-\mathrm{O}$ bonds of hemicellulose & {$[18]$} \\
\hline 1596.9 & 1589.2 & 1643.4 & 1643 & Water adsorbed on the fibers & {$[12,15]$} \\
\hline 1060 & 1060 & 1076 & 1075 & The $\mathrm{C}-\mathrm{O} / \mathrm{C}-\mathrm{C}$ stretching vibrations & [12] \\
\hline- & - & 1176 & 1175 & $\mathrm{Si}-\mathrm{O}-\mathrm{Cellulose}$ & {$[15]$} \\
\hline- & - & 777 & 776 & $\mathrm{Si}-\mathrm{C}$ & {$[19,21]$} \\
\hline - & - & 636 & 636 & $\mathrm{Si}-\mathrm{O}-\mathrm{Si}$ & {$[19,21]$} \\
\hline
\end{tabular}

\section{SEM observations}

Morphological observations were carried out using a scanning electron microscope (Quanta FEG); DPFs were examined before and after chemical treatments as well as after the pull-out test to examine the bonding between the fiber and the matrix. No preliminary sample preparation was carried out.

\section{FTIR spectroscopy}

FTIR measurements of DPFs before and after treatments were performed using IRAffinity-1S spectrometer from SHIMADZU in the range of $400-4000 \mathrm{~cm}^{-1}$. A total of 90 scans were recorded for each sample with a resolution of $16 \mathrm{~cm}^{-1}$, dried fibers were mixed with $\mathrm{KBr}$ and pressed into a disc for measurements.

\section{Contact angle measurement}

To estimate the effect of surface treatment on the hydrophilic/hydrophobic behavior of date palm fibers, contact angle measurements were carried out by depositing $50 \mu \mathrm{L}$ DI water (18.0 M $\Omega$ ) droplets on the DPF. The apparatus used for measurements was a digital camera EasyDrop with digital image analysis software.

\section{Pull-out test}

The pull-out test was performed using a universal testing machine [Model TH $27305 \mathrm{kN}$ (80 W, 500 mm), Germany] with a $5 \mathrm{kN}$ load cell to examine the effect of chemical treatments of DPFs on the fiber-matrix interface, the plot was recorded as load function of pull-out distance; test specimens were prepared by embedding $20 \mathrm{~mm}$ of single fiber in the matrix using a $20 \times 15 \times 10 \mathrm{~mm}$ (length $\times$ width $\times$ thickness) box. The interfacial shear stress (IFSS) was calculated using the following equations:

$\operatorname{IFSS}(\mathrm{MPa})=\frac{F_{\max }}{S_{\text {interface }}}$
$S_{\text {interface }}\left(\mathrm{mm}^{2}\right)=n \times \pi \times D \times L$

With IFSS is the interfacial shear stress (MPa), $F_{\max } \max -$ imum pull-out load $(N), S_{f}$ the surface of fiber-matrix interface $\left(\mathrm{mm}^{2}\right), \mathrm{n}$ number of embedded fibers $(n=1), \mathrm{D}(\mathrm{mm})$ is the fiber diameter and $L(\mathrm{~mm})$ the embedded fiber length.

\section{Results and discussion}

\section{SEM observations of raw and treated DPFs}

Scanning electron microscopy is one of the most powerful characterization technics for assessing the influence of surface modification on fiber topography. SEM micrographs of untreated and treated date palm fibers are shown in Figs. 2, 3 and 4.

Figure 2 shows the effect of alkali treatment on DPF topography. It is clearly seen that alkali treatment improved the surface quality of date palm fibers; indeed, waxes, oils, and other impurities can be clearly seen on the surface of the untreated fiber surface (Fig. 2a). The latters were seen to be removed after treatment due to their solubility in $\mathrm{NaOH}$ aqueous solution as shown in Fig. 2b. Moreover, the fiber surface was seen to be rougher after alkali treatment. This made the hydroxyl groups of the fiber more exposed to the surface and consequently more reactive [12]. Generally, these changes have benefits in composite material manufacture when the fibers are used as reinforcing agents. Indeed, the rougher surface enhances the mechanical interlocking adhesion between the fibers and the matrix materials [15]. SEM images of silane treated DPFs are shown in Figs. 3 and 4.

Although silanes cannot be directly identified by scanning electron microscopy, their effect on the morphology of date palm fibers is important. The treatment of alkalized DPFs with silane A (Fig. 3) or with silane B (Fig. 4) modified the surface appearance of the fibers. Indeed, after the silane A treatment, the surface of the fiber appeared to be 


\section{(a)}

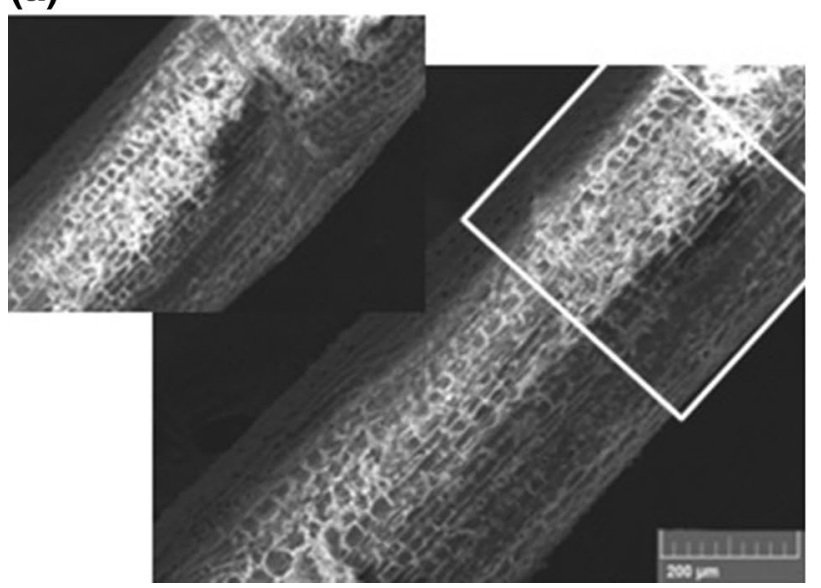

(b)

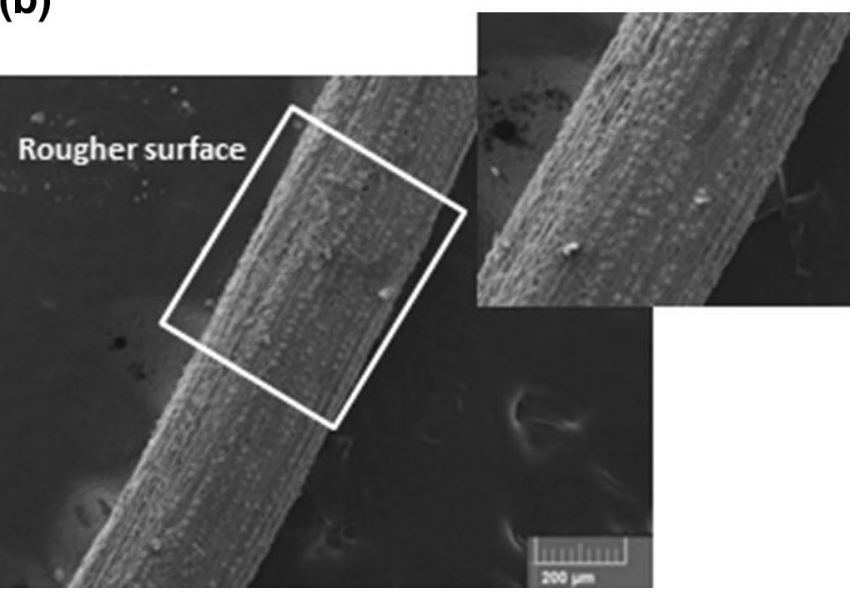

Fig. 2 SEM images of $\mathbf{a}$ untreated DPF and $\mathbf{b}$ alkali treated DPF
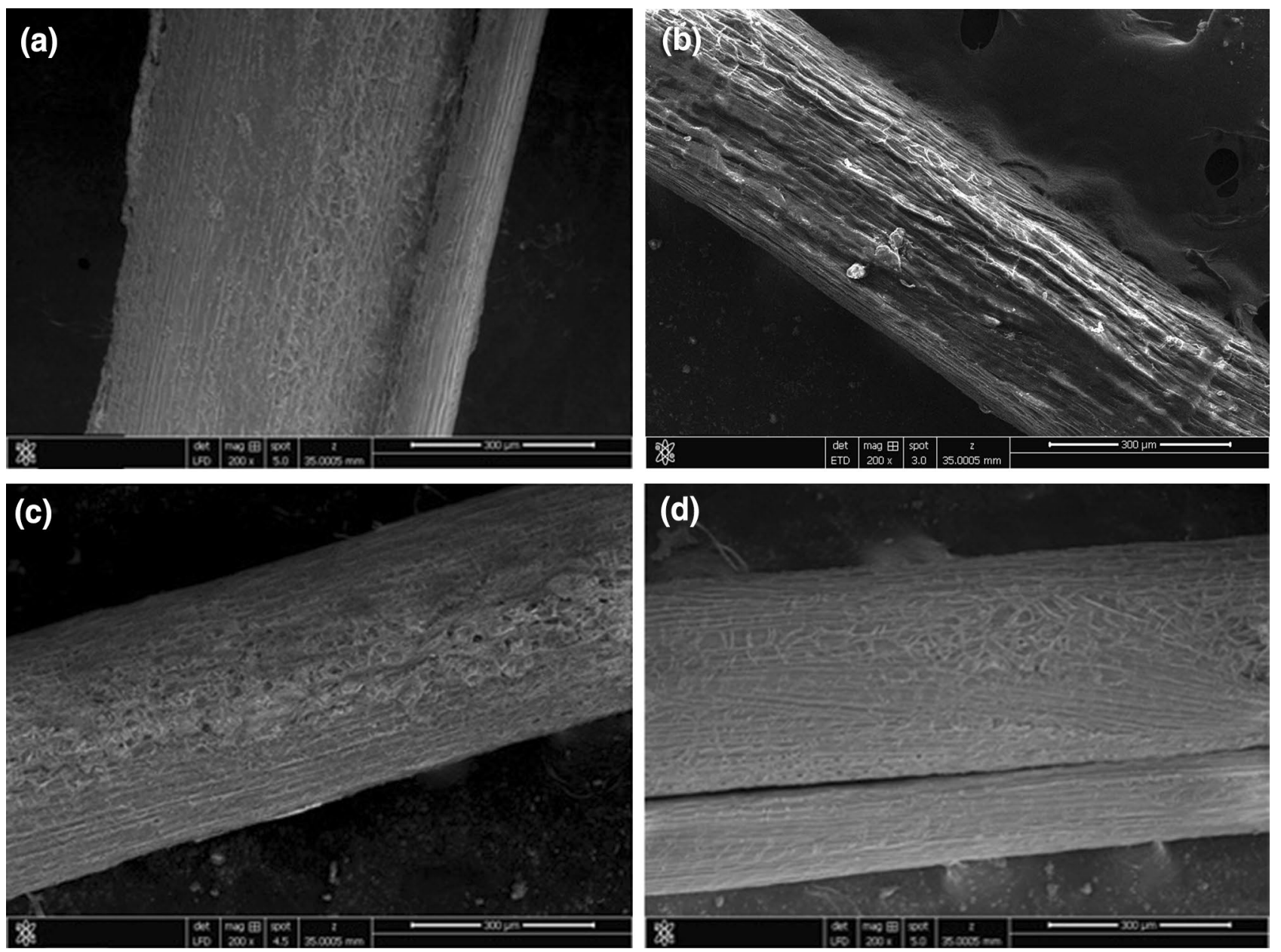

Fig. 3 Surface topography of DPFs after treatment with silane A: a A0.1, b A0.5, c A1 and d A2 

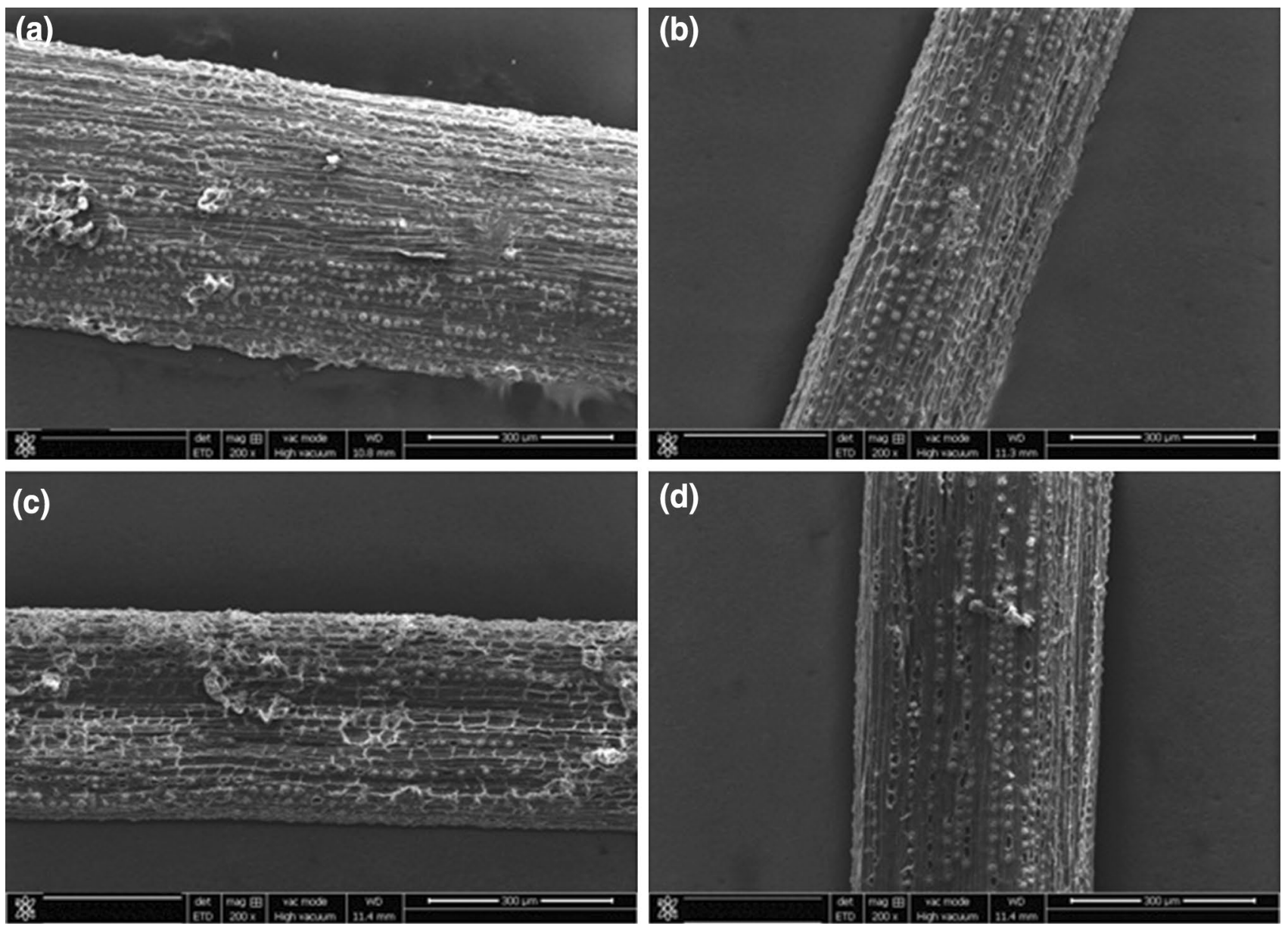

Fig. 4 Fiber surface after treatment with silane B: a B0.1, b B0.5, c B1

smoother to conclude the formation of a surface layer of the silane. After treatment with silane B, the surface texture of the fibers appeared "granular" and "rougher" compared with that of the alkalized fibers (see Fig. 2b). We suggest that silane B partially overlapped the surface or caused cracking of surface microfibrils during drying process. In addition, we noted a densification of the fibers: the hollow structure of the alkalized fibers disappeared after treatment with both organosilane A and B.

FTIR spectroscopy was, therefore, used to confirm the chemical effectiveness of silane treatments by investigating the structural changes in the fiber surface before and after treatment.

\section{FTIR analysis}

FTIR spectra of raw and treated date palm fibers are shown in Fig. 5.

Many chemical changes with different levels have occurred after treatments. The broad absorption band in

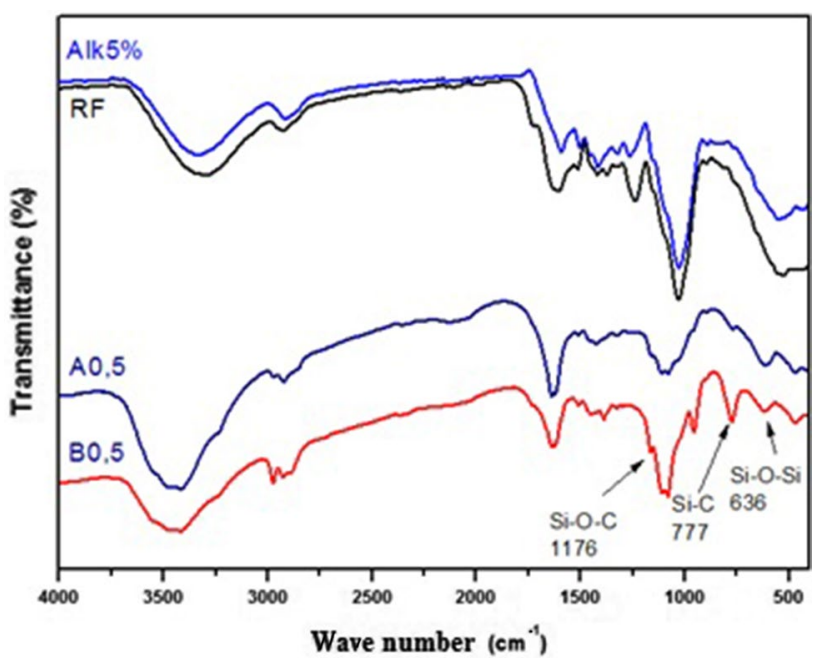

Fig. 5 FTIR spectrum of raw and treated DPFs a silane A and b silane B 
the region between 3200 and $3500 \mathrm{~cm}^{-1}$ is attributed to the vibration of elongation of the $\mathrm{O}-\mathrm{H}$ bond which was found to decrease after alkali treatment, this can be explained by the fact that the hydroxyl groups are involved in hydrogen bonding with the carboxyl groups of the fatty acids available on the fiber surface $[17,18]$. The absorption band in the region around $1745 \mathrm{~cm}^{-1}$ observed in the spectrum of the raw fiber can be attributed to the carbonyl group $\mathrm{C}=\mathrm{O}$ [19], this band disappeared completely after treatment with sodium hydroxide, this disappearance was due to the hydrolysis of hemicellulose in alkaline medium characterized by breaking the $\mathrm{C}-\mathrm{O}-\mathrm{C}$ bonds between two monomers [20]. This implies that hemicelluloses are easily removed by alkalization compared to lignin [12]. The bands at $1176 \mathrm{~cm}^{-1}$ to $1405 \mathrm{~cm}^{-1}$ characteristic of $-\mathrm{O}-\mathrm{CH}_{3}$ and $\mathrm{C}=\mathrm{C}$ bond of lignin, respectively, also decreased after the alkali treatment [20]. After the silane treatment, new absorption bands appeared in the region, from 600 to $1700 \mathrm{~cm}^{-1}$, and are specific to silane coupling agents [21-23]. Indeed, new bands appeared at 1176 and $777 \mathrm{~cm}^{-1}$ which are supposed to come from vibrations of the $\mathrm{Si}-\mathrm{O}-\mathrm{Cellulose}$ and $\mathrm{Si}-\mathrm{C}$ bonds linked to the hydroxyl groups of the fiber surface. The band at $636 \mathrm{~cm}^{-1}$ corresponds to the stretching vibration of the $\mathrm{Si}-\mathrm{O}-\mathrm{Si}$ bonds originating from the condensation of the silane agents [23]. Table 2 regroups the bond assignements of raw and treated DPFs. Therefore, the proposed treatments have been shown to be effective in producing chemically modified DPF surfaces with different functionalities.

\section{The hydrophilic/hydrophobic behavior of treated DPFs}

The effect of silane treatment on the hydrophilic/hydrophobic behavior of DPFs is shown in Fig. 6 .

Contact angle measurements indicate a significant difference in the hydrophilic behavior of raw DPFs compared to silane A and B modified DPFs. From Fig. 6, the contact angle values (hydrophobicity) were found to be growing in the following order: $\mathrm{RF}<$ silane $\mathrm{A}<$ silane $\mathrm{B}$. We note that the high value of the relative contact angle has been reached with organosilane B-treated DPFs, despite the presence of an amino terminal group having a high polarity. This result was attributed to the configuration of this silane at the surface of the fibers which is supposed to bend and orient its polar head $\left(\mathrm{NH}_{2}\right)$ towards the surface, driven by the formation of strong hydrogen bonds with the hydroxyl groups of the DPFs. It is likely that the rapid rate of condensation of $(-\mathrm{Si}-\mathrm{OH}+-\mathrm{Si}-\mathrm{OH})$ and $(-\mathrm{Si}-\mathrm{OH}+\mathrm{C}-\mathrm{OH})$, induced by the catalytic effect of the amine group, resulted in a lower concentration of the $\mathrm{Si}-\mathrm{OH}$ groups free on the surface. Such a configuration would leave the ethylene groups exposed to the surface, thus leading to the hydrophobicity being evaluated
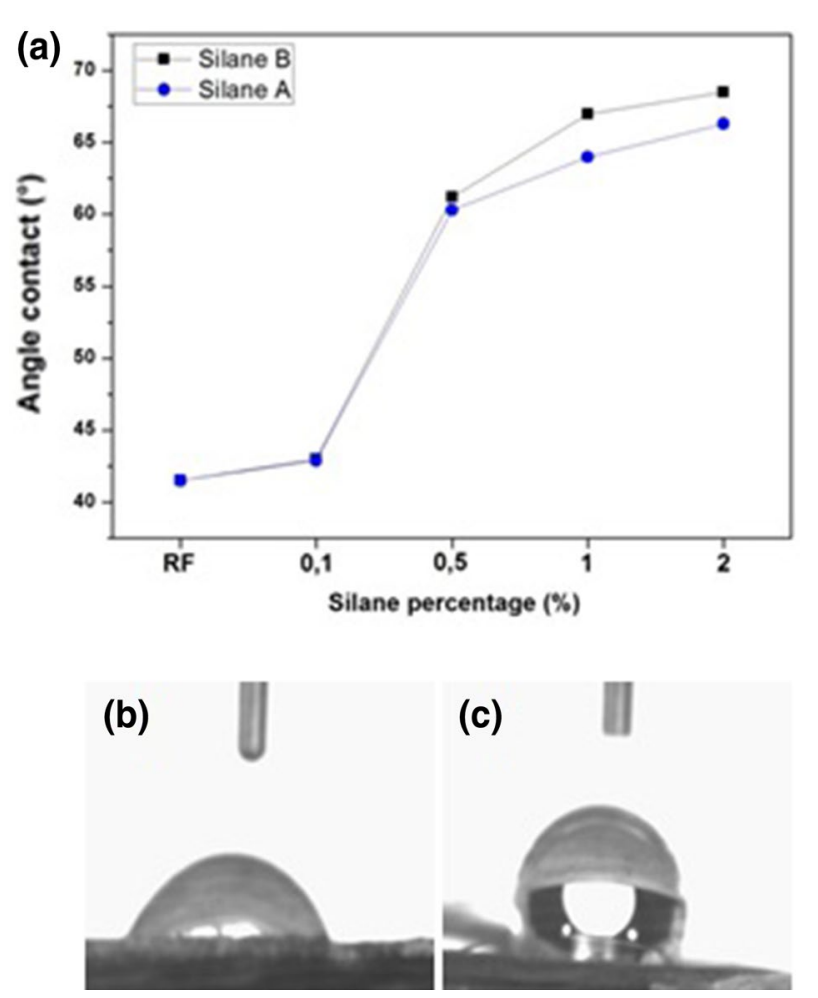

Fig. 6 a Contact angle measurements for raw and alkali-silane treated DPFs and Water droplet on $\mathbf{b}$ raw fiber surface and $\mathbf{c}$ A2 treated surface

through the contact angle. This catalytic effect of organosilanes had been widely studied in the literature [21].

Similar results had been reported by Mansur et al. [24] who have studied the effect of organosilane treatment on the hydrophobicity of fibers using several types of organosilanes. The authors concluded that the contact angle increased in the following order according to the organosilane used:

Silane A $<3$ - methacryloxy - propyl

- trimethoxysilane $<3$ - isocyanate

- propyl - triethoxysilane

$<$ Silane B $<$ Vinyl - trimethoxysilane.

\section{Interfacial properties of DPF-Polyurethane and DPF-Epoxy systems}

Up to now, we have presented the effect of treatment with two different organosilanes (silane A: 3-mercatopropyltrimethoxysilane and silane B: 3-aminopropyltrimethoxysilane) on the surface of the alkalized date palm fibers (5\% of $\mathrm{NaOH}$ ). Our main goal is to improve the interfacial properties of DPFs with organic matrices. To do this, pull-out tests were carried out on DPF-polyurethane and DPF-epoxy 
Table 3 Bonding characteristics of A-PU and B-PU systems

\begin{tabular}{llll}
\hline A-PU system & IFSS $(\mathrm{MPa})$ & B-PU system & IFSS (MPa) \\
\hline RF-PU & $0.18 \pm 0.006$ & - & - \\
A0.1-PU & $0.30 \pm 0.008$ & B0.1-PU & $0.35 \pm 0.005$ \\
A0.5-PU & $0.39 \pm 0.007$ & B0.5-PU & $0.42 \pm 0.008$ \\
A1-PU & $0.38 \pm 0.01$ & B1-PU & $0.39 \pm 0.007$ \\
A2-PU & $0.35 \pm 0.007$ & B2-PU & $0.32 \pm 0.005$ \\
\hline
\end{tabular}

Table 4 Bonding characteristics of A-Epoxy and B-Epoxy systems

\begin{tabular}{llll}
\hline A-Epoxy system & IFSS (MPa) & B-Epoxy system & IFSS (MPa) \\
\hline RF-Epoxy & $0.22 \pm 0.01$ & - & - \\
A0.1-Epoxy & $0.31 \pm 0.009$ & B0.1-Epoxy & $0.33 \pm 0.009$ \\
A0.5-Epoxy & $0.40 \pm 0.01$ & B0.5-Epoxy & $0.41 \pm 0.008$ \\
A1-Epoxy & $0.41 \pm 0.008$ & B1-Epoxy & $0.42 \pm 0.006$ \\
A2-Epoxy & $0.36 \pm 0.007$ & B2-Epoxy & $0.35 \pm 0.006$ \\
\hline
\end{tabular}

systems to evaluate the effectiveness of these treatments on the quality of adhesion between the fibers and the polymer matrices. The results obtained are summarized in Tables 3 and 4 .
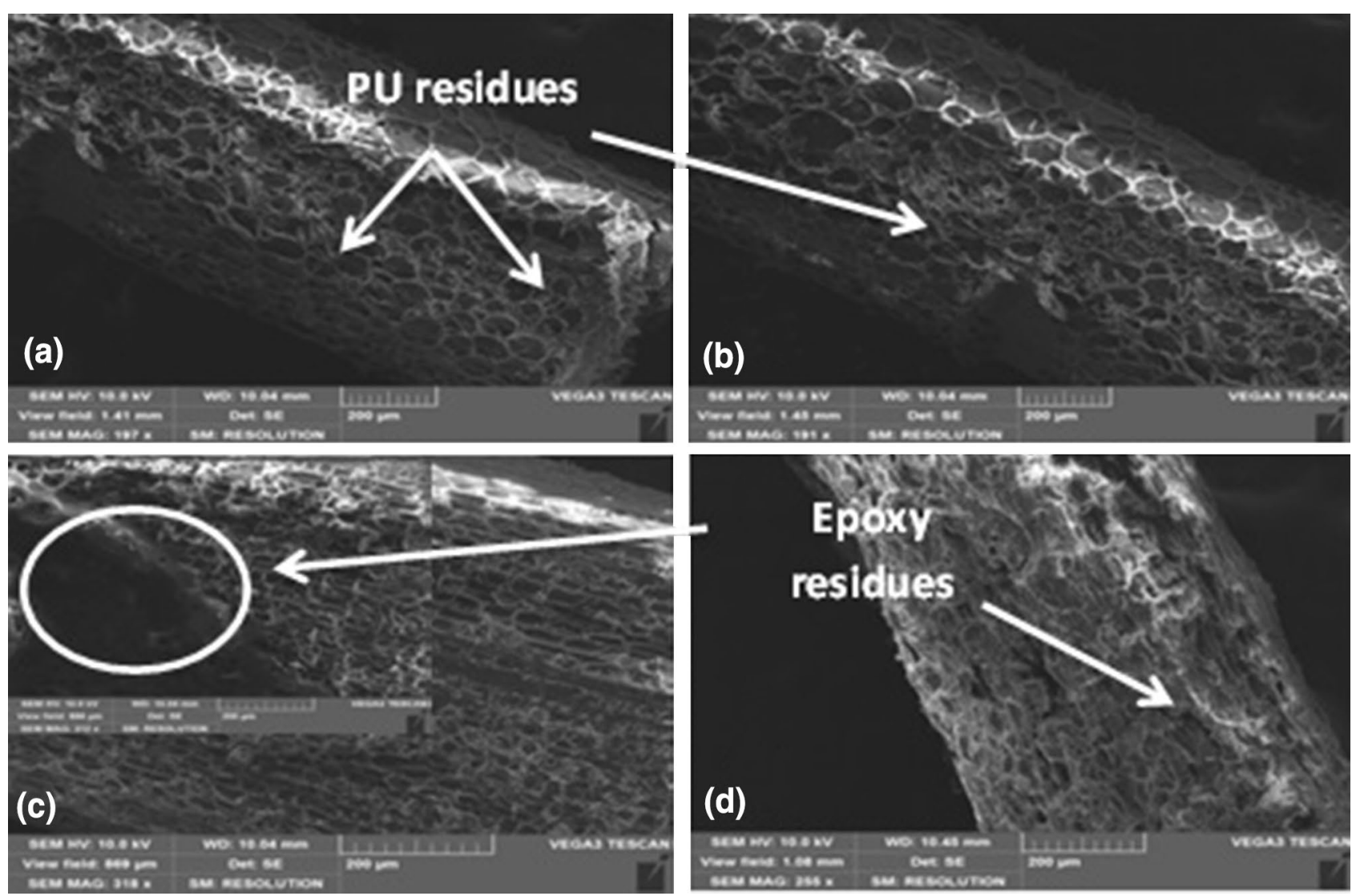

Fig. 7 SEM images of DPFs pulled-out of different systems a A0.5-PU, b B0.5-PU, c A1-Epoxy and d B1-Epoxy 


\section{SEM observation of the pulled-out DPFs}

Figure 7 shows the SEM images of the date palm fibers obtained after the pull-out tests of the DPF-PU and DPFEpoxy systems.

From Fig. 7 one can see clearly that the surface of the raw fiber pulled out from the matrix was not subjected to any abrasion. This can be explained by the lack of compatibility between the fiber and the matrix. The residues of the organic matrices can be clearly seen on the surface of the fibers. This means the existence of a strong attachment between the two materials translated by the formation of strong links to the interface. These observations explain the increase in interfacial stress between DPFs and organic matrices after organosilane treatment.

\section{Conclusion}

To conclude, the experimental results presented in this paper have shown that the chemical treatments of date palm fibers in particular, the alkali treatment and the treatment with organosilanes have remarkably improved the interfacial characteristics between the fibers and the organic matrices such as polyurethane and epoxy evaluated by the pull-out tests. Indeed, the treatment with organosilanes A and B of alkalized DPFs with $5 \%$ of $\mathrm{NaOH}$ made it possible to considerably increase the interfacial strength of the FPD-PU and FPD-Epoxy systems. Optimum concentrations were recorded at $0.5 \%$ for A-PU and B-PU systems and $1 \%$ for A-Epoxy and B-Epoxy systems.

Open Access This article is distributed under the terms of the Creative Commons Attribution 4.0 International License (http://creativeco mmons.org/licenses/by/4.0/), which permits unrestricted use, distribution, and reproduction in any medium, provided you give appropriate credit to the original author(s) and the source, provide a link to the Creative Commons license, and indicate if changes were made.

\section{References}

1. Alvarez VA, Vazquez A (2006) Influence of fiber chemical modification procedure on the mechanical properties and water absorption of MaterBi-Y/sisal fiber composites. Compos A Appl Sci Manuf 37(10):1672-1680

2. Barreto A et al (2010) Cardanol biocomposites reinforced with jute fiber: microstructure, biodegradability, and mechanical properties. Polym Compos 31(11):1928-1937

3. Oushabi A et al (2015) Natural thermal-insulation materials composed of renewable resources: characterization of local date palm fibers (LDPF). J Mater Environ Sci 6(12):3395-3402

4. Al-Oqla FM, Sapuan S (2014) Natural fiber reinforced polymer composites in industrial applications: feasibility of date palm fibers for sustainable automotive industry. J Clean Product 66:347-354
5. Benzerzour M et al (2012) Waste fibre-cement matrix bond characteristics improved by using silane-treated fibres. Constr Build Mater 37:1-6

6. Pothan LA, Thomas S (2003) Polarity parameters and dynamic mechanical behaviour of chemically modified banana fiber reinforced polyester composites. Compos Sci Technol 63(9):1231-1240

7. Witucki GL (1993) A silane primer: chemistry and applications of alkoxy silanes. J Coat Technol 65:57-57

8. Bilba K, Arsene MA (2008) Silane treatment of bagasse fiber for reinforcement of cementitious composites. Compos A Appl Sci Manuf 39(9):1488-1495

9. Aboudzadeh M, Mirabedini S, Atai M (2007) Effect of silanebased treatment on the adhesion strength of acrylic lacquers on the PP surfaces. Int J Adhes Adhes 27(7):519-526

10. Li Y, Mai Y-W, Ye L (2005) Effects of fibre surface treatment on fracture-mechanical properties of sisal-fibre composites. Compos Interfaces 12(1-2):141-163

11. Sawpan MA, Pickering KL, Fernyhough A (2011) Effect of various chemical treatments on the fibre structure and tensile properties of industrial hemp fibres. Compos A Appl Sci Manuf 42(8):888-895

12. Oushabi A et al (2017) The effect of alkali treatment on mechanical, morphological and thermal properties of date palm fibers (DPFs): study of the interface of DPF-Polyurethane composite. S Afr J Chem Eng 23:116-123

13. Hojo T et al (2014) Tensile Properties of Bamboo, Jute and Kenaf Mat-reinforced Composite. Energy Procedia 56:72-79

14. Liu XY, Dai GC (2007) Surface modification and micromechanical properties of jute fiber mat reinforced polypropylene composites. Express Polym Lett 1(5):299-307

15. Zhou F, Cheng G, Jiang B (2014) Effect of silane treatment on microstructure of sisal fibers. Appl Surf Sci 292:806-812

16. Michelena AH et al (2017) Silane modification of the flax/epoxy system interface. Procedia Eng 200:448-456

17. Mwaikambo LY, Ansell MP (2002) Chemical modification of hemp, sisal, jute, and kapok fibers by alkalization. J Appl Polym Sci 84(12):2222-2234

18. Shokri A, Rabiee F, Mahanpoor K (2017) Employing a novel nanocatalyst (Mn/Iranian hematite) for oxidation of $\mathrm{SO}_{2}$ pollutant in aqueous environment. Int $\mathrm{J}$ Environ Sci Technol 14(11):2485-2494

19. Shokri A, Mahanpoor K, Soodbar D (2016) Evaluation of a modified $\mathrm{TiO}_{2}\left(\mathrm{GO}-\mathrm{B}-\mathrm{TiO}_{2}\right)$ photo catalyst for degradation of 4-nitrophenol in petrochemical wastewater by response surface methodology based on the central composite design. J Environ Chem Eng 4(1):585-598

20. Alawar A, Hamed AM, Al-Kaabi K (2009) Characterization of treated date palm tree fiber as composite reinforcement. Compos Part B Eng 40(7):601-606

21. Abdelmouleh M et al (2005) Modification of cellulose fibers with functionalized silanes: effect of the fiber treatment on the mechanical performances of cellulose-thermoset composites. J Appl Polym Sci 98(3):974-984

22. Salon MC et al (2005) Silane adsorption onto cellulose fibers: hydrolysis and condensation reactions. J Colloid Interface Sci 289(1):249-261

23. Abdelmouleh $\mathrm{M}$ et al (2002) Interaction of silane coupling agents with cellulose. Langmuir 18(8):3203-3208

24. Mansur AAP et al (2008) Chemical functionalization of ceramic tile surfaces by silane coupling agents: polymer modified mortar adhesion mechanism implications. Mater Res 11(3):293-302

Publisher's Note Springer Nature remains neutral with regard to jurisdictional claims in published maps and institutional affiliations. 